\title{
A DUPLA IMPLICAC̣ÃO DA EPOCHE E SUA RELAÇÃO COM O MUNDO NA FENOMENOLOGIA DE HUSSERL ${ }^{1}$
}

Carlos Diógenes C. Tourinho (UFF) ${ }^{2}$

cdctourinho@yahoo.com.br

Resumo: $O$ presente artigo tem como objetivo investigar a relação entre a epoché fenomenológica e o problema fenomenológico da relação entre a consciência e o mundo. Inicialmente, o artigo examina a primeira implicação do exercício da epoché: a ideia da "perda do mundo." Em seguida, examina a segunda implicação deste exercício: a ideia da "recuperação do mundo" na consciência transcendental. Finalmente, o artigo esclarece a especificidade do idealismo fenomenológico de Husserl $\mathrm{O}$ exercício generalizado da epoché não implica em uma negação da existência do mundo. A tarefa deste idealismo é elucidar fenomenologicamente o sentido deste mundo que se forma intencionalmente na subjetividade transcendental.

Palavras-chave: Consciência; mundo; epoché; idealismo fenomenológico.

\section{INTRODUÇÃO}

Pode-se dizer que o acompanhamento atento do itinerário traçado por Husserl - a partir dos cursos oferecidos ao final da primeira década do século XX e, especialmente, a partir da publicação do primeiro volume de Ideias para uma fenomenologia pura e filosofia fenomenológica, em 1913 - permitenos notar, muito claramente, uma estreita conexão entre a estratégia metodológica adotada pela fenomenologia para a

\footnotetext{
${ }^{1}$ Recebido: 13-05-2015/ Aceito: 27-11-2015/ Publicado on-line: 28-08-2016.

${ }^{2}$ Carlos Diógenes C. Tourinho é Professor Adjunto do Departamento de Filosofia da Universidade Federal Fluminense, Niterói, RJ, Brasil.
} 
evidenciação plena do que aparece à consciência e as considerações husserlianas sobre o problema fenomenológico da relação entre a consciência e o mundo. Afinal, a generalização da chamada "epoché fenomenológica" impõe-nos uma mudança de posição em relação ao mundo, deslocando-nos a atenção de um modo empírico-natural de consideração do mundo, próprio da vida habitual dos homens, bem como das ciências positivas, para um novo modo de consideração a partir do qual visamos apreender o que aparece à consciência em seu sentido originário, em sua "ipseidade de carne e osso" (in seiner "leibhaften" Selbstheit), como prefere o próprio Husserl, no $\S 3$ de Ideias I. A referida mudança de posição proporcionada pela epoché permite-nos, por sua vez, falar de um mundo do qual partimos empiricamente, vivenciado continuamente por nós mesmos - enquanto homens efetivos, entes psicofísicos - mas, sobre o qual lançamos uma suspensão de juízo, colocando "entre parênteses" a posição de existências das coisas que habitam este mundo. Por outro lado, o exercício generalizado de tal estratégia metodológica nos permitirá, de certo modo, falar de uma "nova versão" do mundo: o mundo tal como revelado e constituído na própria imanência da consciência intencional.

Tem-se, portanto, neste período do itinerário husserliano, a apresentação ao leitor da ideia segundo a qual o exercício da epoché fenomenológica teria uma "dupla implicação": implicaria, por um lado, em uma espécie de "perda do mundo" e, por outro, em um "ganho" ou uma "recuperação do mundo" na própria consciência que o intenciona. Tal consciência seria, para Husserl, uma consciência transcendental (independente de - e anterior a - toda descrição psicológica), em cuja imanência o "novo mundo" 
seria, então, revelado e constituído. Vemos, por exemplo, em um curso de 1909 - intitulado Ideia da fenomenologia e seu método - Husserl afirmar que: "Perdemos o mundo, para ganhá-lo de um modo mais puro, retendo o seu sentido. A fenomenologia põe fora de circuito a realidade da natureza... mas retém, por assim dizer, a alma, o sentido de tudo isso com o qual estou imediatamente em contato [...]" (apud FRAGATA, 1956, p. 113). Ou ainda, em outra passagem, em 1913, no $§ 50$ de Ideias I, na qual o autor afirma que: "[...] ainda que nós tenhamos colocado 'fora de circuito' o mundo inteiro, com todas as coisas [...] ganhamos a totalidade do ser absoluto que abriga e constitui em si todas as transcendências do mundo" (HUSSERL, [1913] 1976, p. 107). Ou seja, enquanto uma estratégia metodológica adotada pela fenomenologia, o exercício generalizado da suspensão de juízo em relação à posição de existência das coisas que habitam o mundo não impede - antes sim, torna possível - a abertura de um campo sobre o qual a fenomenologia dirigiria o seu olhar: o que poderíamos, num primeiro momento, chamar de "campo fenomenal", em cuja imanência todas as transcendências do mundo (no sentido do que se encontra fora da consciência) seriam recuperadas, reveladas e constituídas intencionalmente. Tal investigação fenomenológica procuraria elucidar o sentido originário de tudo o que se mostra apoditicamente neste campo fenomenológico, caminho que, para Husserl, nos conduziria a uma compreensão definitiva do mundo. Tal compreensão equivaleria, nos termos de Quentin Lauer, a uma "penetração no sentido do mundo” (LAUER, 1954, p. 36). Daí o próprio Husserl dizer, na Introdução de Lógica Formal e Lógica Transcendental (1929), que: "É somente um mundo clarificado pela fenomenologia transcendental que pode ser um 
mundo definitivamente compreendido" (HUSSERL, [1929] 1981, p. 14).

A leitura atenta dos textos de Husserl permite-nos notar, portanto, neste período que marca época com a publicação de Ideias I, em 1913, mas também em passagens subsequentes, uma relação estreita entre o exercício da epoché fenomenológica e o problema fenomenológico da relação entre a consciência e o mundo. Vale lembrar o importante artigo escrito por Landgrebe, na década de 40 (intitulado "The World as a Phenomenological Problem"), no qual nos chama a atenção, especificamente, neste período do itinerário husserliano, para o que considera uma das principais vias de investigação do problema fenomenológico do mundo, na qual o conceito de "mundo" se encontra "em conexão com o problema da redução fenomenológica" (LANDGREBE, 1940, pp. 38-39). O presente artigo terá como objetivo principal investigar tal conexão entre a estratégia metodológica adotada pela fenomenologia e as considerações husserlianas sobre o problema fenomenológico da relação entre a consciência e o mundo .

Vê-se ainda, em algumas passagens do texto de Husserl, que a estratégia da epoché - apesar dos "parênteses lançados" sobre a posição de existência das coisas - não abalaria, por um lado, a afirmação da existência do mundo, o que sugeriria, ao leitor, num primeiro momento, a aceitação de uma espécie de "realismo" no projeto da fenomenologia husserliana. Por outro lado, o exercício desta mesma estratégia nos levaria à afirmação da tese segundo a qual qualquer referência ao mundo - conforme veremos, ao sentido do mundo - já suporia uma consciência originária, doadora de sentidos, o que sugeriria ao leitor a aceitação, por parte de Husserl, de um tipo de idealismo. Esta aparente ambi- 
guidade no posicionamento de Husserl quanto à relação entre a consciência e o mundo tem levado alguns comentadores, como Vann de Pitte (1981), a observar que a fenomenologia tem recebido, nas últimas décadas, interpretações diversas: alguns autores a consideram como um realismo, ao passo que outros a consideram como um novo idealismo na filosofia contemporânea. $\mathrm{O}$ mesmo comentador nos diz que "é indiscutível que ambas as interpretações podem ser acentuadamente sustentadas com evidência textual" (VAN DE PITTE, 1981, p. 39). E ainda, afirma que os escritos de Husserl sugerem inumeráveis ambiguidades a esse respeito, na medida em que nos forçam a admitir que "[...] o mundo existe e não existe independentemente da consciência” (Idem., p. 40). Já Karl Ameriks (1977) e John Findlay (1975) inclinam-se para uma interpretação "realista" da fenomenologia de Husserl. O segundo afirma que "Husserl não forneceu uma razão boa ou mesmo significativa para duvidarmos da existência do mundo" (FINDLAY, 1975, p. 156). Por outro lado, Robert Solomon coloca a seguinte questão: "Se o ego constitui seus objetos, que fundamento fenomenológico pode haver para supor que o mundo tem alguma existência independentemente de sua criação pelo ego?" (apud AMERIKS, 1977, p. 512). Já André de Muralt (1974) observa que, em Husserl, não se trata de "escolher entre realismo e idealismo, no sentido usual destas duas palavras, isto é, entre o ego e a coisa [...]. Nós devemos, por conseguinte, escolher ambos o ego e a coisa e mostrar a sua correlação, sua simultaneidade constitutiva" (MURALT, 1974, p. 120) .

A despeito das divergências entre os comentadores, o leitor poderá se colocar, muito brevemente, a partir da investigação da relação entre a dupla implicação da epoché e as 
considerações husserlianas sobre o mundo, as seguintes questões: em que sentido devemos entender a ideia da "perda do mundo" (primeira implicação da epoché)? Ela implicaria em uma "negação" do mundo circundante no qual nos inserimos como homens efetivos ou seria compatível com algum tipo de realismo? Por outro lado, como devemos entender a ideia deste tal "mundo recuperado" (segunda implicação da epoché): como sentido do mundo que somente se revela em uma objetividade imanente, sem relação alguma com o que é exterior à consciência ou seria incompatível com um idealismo que negasse tal exterioridade? Afinal, qual a especificidade deste "novo idealismo", anunciado por Husserl no século XX sob o nome de "fenomenologia transcendental"? É o que examinaremos mais detidamente a partir de agora.

\section{O DESAFIO METODOLÓGICO E A "PRIMEIRA IMPLICACุÃO” DA EPOCHÉ FENOMENOLÓGICA}

É na medida em que compreendemos o desafio metodológico enfrentado por Husserl já no início do século XX, bem como a estratégia metodológica adotada pela fenomenologia para a superação deste desafio, que elucidamos o sentido husserliano da ideia de uma "perda do mundo" que, por sua vez, poderia, num primeiro momento, sugerir ao leitor a ideia de uma "negação" do mundo. A compreensão de tal desafio e da especificidade da referida estratégia metodológica explicitará, ao contrário, que não se trata, com a orientação fenomenológica, de uma "negação", mas sim, de uma "renúncia" ao que Husserl considera um modo ingênuo de posicionamento perante o mundo ("despreocupado" quanto aos problemas da possibilidade de conhecê-lo), adotado 
habitualmente pelos homens e pelas ciências da natureza. Como nos lebra Quentin Lauer, a fenomenologia "[...] é um esforço sistemático para transformar a aceitação ingênua de um mundo em um conhecimento essencial do mundo" (LAUER, 1954, p. 39). Tal renúncia a este modo ingênuo de consideração do mundo somente se torna possível por meio de uma "conversão" à posição fenomenológica - que, para Husserl, não é senão "a posição intelectual, especificamente, filosófica [...]” (HUSSERL, [1907] 1950, p. 23) - frente ao mundo circundante natural (natürliche Umwelt).

Pode-se dizer que, a partir das primeiras décadas do século XX, ao anunciar, com a "nova fenomenologia", a especificidade de um novo modo de consideração, bem como de um método de evidenciação do mundo, um desafio peculiar se impunha a Husserl, a saber: a exigência de adotar uma estratégia metodológica por intermédio da qual pudesse se abrir, sem que fosse negada a existência do mundo, o que poderíamos chamar, num primeiro momento, de "campo fenomenal", em cuja imanência tudo aquilo que aparecesse pudesse, então, se dar originariamente e, portanto, com evidenciação máxima, livre das limitações que a relação empírica com o "mundo circundante" insiste em nos impor.

Como um recurso metodológico para o alcance de tais evidenciações apodíticas, Husserl opta pelo exercício da epoché, isto é, da "suspensão de juízo" em relação à posição de existência das coisas. Nos termos de Husserl, promovo a "colocação da atitude natural entre parênteses", a facticidade do mundo fica "fora de circuito". Não deixo, contudo, de vivenciar a "tese do mundo", segundo a qual o que chamamos de "mundo" encontra-se simplesmente aí, diante de 
nós, tudo isto que, da maneira a mais imediata e direta, nos é revelado através da experiência sensível. No entanto, apesar de vivenciar a "tese do mundo", como diz o $\$ 31$ de Ideias I, não faço mais uso dessa tese, procuro mantê-la fora de circuito. Renunciamos a um modo ingênuo de consideração do mundo, no qual o mundo aparece, em sua versão empírica, como "mundo de fatos", para reavê-lo na consciência intencional. Daí o próprio Husserl retomar, uma vez mais, alguns anos mais tarde, a ideia da perda e do ganho do mundo, na Conclusão de suas Meditações Cartesianas, em 1931, afirmando-nos que: "Antes de mais nada, é preciso perder o mundo pela epoché para reencontrá-lo numa tomada de consciência universal de si próprio" (HUSSERL, [1931] 1973, p. 183).

Observa-se, inicialmente, em relação à ideia da "perda do mundo", o que poderíamos considerar a primeira implicação do exercício da epoché fenomenológica: se o ponto de partida da fenomenologia é a tese do mundo e, portanto, a relação empírica do homem com o mundo natural, é preciso observar que Husserl não visa, em momento algum, ao exercer a epoché sobre a referida tese, colocando-a "entre parênteses”, negar a existência do mundo. Daí o próprio autor afirmar, no $§ 32$ de Ideias I: “[...] não nego este 'mundo', como se eu fosse um sofista, não duvido de sua existência, como se fosse cético, mas efetuo a epoché fenomenológica" (HUSSERL, [1913] 1976, p. 65). Ainda em outra passagem, no primeiro volume de sua Filosofia Primeira (1923-1924), Husserl nos diz que: "A genuína filosofia transcendental [...] não é como a de Hume, nem abertamente, nem subrepticiamente uma cética dissolução do conhecimento do mundo e do mundo ele mesmo em ficções [...]" (HUSSERL, [1924] 1970, p. 310). Portanto, se a epoché 
permite-nos operar uma mudança de posição em relação ao mundo, não é no sentido de que tal mudança force-nos a exercer uma negação do mundo circundante natural - como nos diz Georges Gurvitch, "[...] ela não nega e nem destrói nada" (GURVITCH, 1949, p. 29) - mas sim, no sentido de que, com a suspensão de juízo, estaríamos nos abstendo de tecer considerações sobre a posição existencial das coisas. Afinal, conforme Husserl insiste em nos mostrar, quando exercemos a redução fenomenológica, procurando reter, por variações imaginárias, a "essência ou sentido genérico" (generellen Wesen oder Sinn) do que é intencionado no pensamento, é irrelevante a posição de existência do que é visado. Seja como um fato real, como um sonho, como uma alucinação, etc., o eidos do que é intencionado no pensamento se mantém invariavelmente o mes$\mathrm{mo}^{3}$.

Se o desafio metodológico enfrentado por Husserl, bem como a estratégia metodológica adotada para superá-lo, permitem-nos elucidar a ideia da "perda do mundo", por outro lado, tal elucidação revela-nos que, mesmo com a epoché, permanecemos ligados ao mundo do qual partimos

\footnotetext{
3 “Temos, em Husserl, uma eidética (ou uma 'doutrina de essências'). A 'essência' deve ser entendida como aquilo que é retido no pensamento através da 'redução eidética'. Nos termos de Husserl, ainda em 1907: 'com a redução fenomenológica, passamos do fato individual para o que há nele de genérico'. Portanto, pode-se entender esta essência como aquilo que é retido no pensamento pela técnica de variação imaginária dos objetos: atenho-me, ao exercer a redução eidética, ao núcleo invariante da coisa, isto é, ao que persiste na coisa mesmo diante de todas as variações a que eu a submeto em minha imaginação. Procuro, portanto, ao tomar a coisa como um cogitatum (isto é, como um objeto de pensamento), reter no próprio ato intencional do pensamento aquilo sem o qual seria impossível tomar este cogitatum como este (e não como outro) objeto intencional imanente ao pensamento". Cf. Tourinho, C. D. C. "Fenomenologia e Ciências Humanas: sobre as considerações de Jean-François Lyotard", p. 207. Nas "Cinco Lições", Husserl reitera que, para a consideração de essências, é irrelevante a posição de existência. Daí o próprio autor nos dizer que: "Para a consideração de essências, a percepção e a representação da fantasia estão no mesmo pé de igualdade; a partir de ambas se pode destacar igualmente bem e abstrair a mesma essência, e as posições de existência nelas entremeadas são irrelevantes". Cf. Husserl, E. Die Idee der Phänomenologie - Fünf Vorlesungen, pp. 68/69.
} 
como homens efetivos, porém, não mais procuramos extrair o modo de consideração acerca das coisas daquilo que nos é revelado empiricamente. Neste sentido, ao se referir ao exercício da epoché em relação à "tese do mundo", em momento algum, Husserl nega a existência do mundo, apenas renuncia a fazer uso da referida tese. Daí o próprio Husserl dizer, muito claramente, no $\S 31$, de Ideias I, a propósito do exercício da epoché e da sua relação com a tese do mundo: "Não se trata de uma transformação da tese na antítese, da posição em negação [...] não alteramos em nada a nossa persuasão [...]” (HUSSERL, [1913] 1976, p. 63). Tratase, antes sim, apenas de uma modificação: a tese do mundo permanece em si mesma o que ela é; apenas colocamo-la "entre parênteses". Nos termos de Husserl, ainda no mesmo parágrafo: "A tese continua, como o que está entre parênteses continua dentro dos parênteses, ou como o que está fora de circuito continua fora da conexão do circuito. Podemos mesmo dizer que vivemos a tese, mas não fazemos 'nenhum uso' dela” (HUSSERL, [1913] 1976, p. 63). Husserl alerta-nos, contudo, que o não fazer "nenhum uso" (keinen Gebrauch) da tese não deve ser entendido como "privação" da tese do mundo, "como quando dizemos que perdemos a consciência e não fazemos uso de tese alguma" (Idem, p. 63).

Exatamente por conta da conservação da tese do mundo "dentro dos parênteses" - uma "tese" da qual partimos como homens efetivos antes mesmo da epoché, vivida continuamente por nós mesmos como "entes psicofísicos", mas da qual não mais fazemos uso a partir da epoché - que Husserl é levado, em diferentes momentos, a preservar a afirmação da existência do mundo. Ainda nas "Cinco Lições" de 1907, Husserl afirma-nos que: "[...] nenhum ser racional 
duvidará da existência do mundo e o cético é desmentido pela sua prática" (HUSSERL, [1907] 1950, p. 36). Novamente, no primeiro volume de sua Filosofia Primeira (1923. 1924), Husserl afirma categoricamente: "É evidente que o mundo é o que é, em si e por si, quer vivamos ou morramos, quer o conheçamos ou não" (HUSSERL, [1924] 1970, p. 308). Ou ainda, em uma passagem do prefácio à edição inglesa de Ideias I, de 1930: "Que o mundo existe [...] está inteiramente fora de dúvida” (HUSSERL, [1930] 1981, p. 48) .

O caráter indubitável da existência do mundo é ainda afirmado, em Husserl, a propósito da temática da "convergência" dos traços (ou esboços) de tudo aquilo que se mostra empiricamente. Por mais perfeita que seja uma percepção empírica, conforme nos alerta Husserl, no § 41 de Ideias I, ela será sempre a percepção de um ponto de vista e, como tal, somente poderá revelar "aspectos" ou "perspectivas" da coisa percebida que, por sua vez, apenas se mostrará parcialmente. O que quer que seja percebido empiricamente apresenta-se em uma sucessão de diversos aspectos ou perspectivas, num "agora" continuamente novo. Neste sentido, o que é percebido empiricamente se mostra, parcialmente, de perto, de longe, deste ou daquele lado, etc. em uma série de aparências continuamente diversas e incompletas ("Uma coisa, por princípio, só pode ser dada "por um de seus lados'”) (HUSSERL, [1913] 1976, p. 91). Husserl chama-nos a atenção, no $§ 41$ de Ideias I, para a "admirável convergência” de tais traços ou esboços da coisa percebida através da qual somos, naturalmente, levados a afirmar a existência desta mesma coisa. Por fim, no $§ 46 \mathrm{da}$ mesma obra, o autor nos diz que tal convergência já seria uma forte razão a favor da existência do mundo. Em seus 
próprios termos: "O mundo não é duvidoso no sentido de que existam motivos racionais contra a maravilhosa força das experiências convergentes [...]” (HUSSERL, [1913] 1976, pp. 98-99).

Portanto, a ideia husserliana de uma "perda do mundo" - primeira implicação do exercício da epoché fenomenológica - não implicaria em uma "negação" do mundo. Lembremos aqui do importante artigo de Eugen Fink, de 1933 (intitulado "Die phänomenologische Philosophie Edmund Husserls in der gegenwärtigen Kritik"), no qual nos chama a atenção para o sentido fenomenológico da ideia do que significa "transcender o mundo" pela estratégia metodológica adotada pela fenomenologia, afirmandonos que "[...] transcender o mundo, como se faz na redução fenomenológica, não é sair do mundo, esquivar-se do mundo para procurar uma origem separada do mundo [...]" (FINK, 1933, p. 342). Ao contrário, nos diz o célebre colaborador de Husserl, transcender o mundo em sentido fenomenológico é, para a subjetividade transcendental, se "abrir ao mundo" e introduzir o mundo no universo desobstruído do "ser" absoluto. "O mundo permanece imanente ao 'Absoluto' - ou antes, é descoberto como situado no Absoluto” (Idem., p. 342). Faz-se necessário elucidar, então, a partir de agora, em que sentido este tal mundo é "recuperado" - nos termos de Fink, "aberto" ou "introduzido" em uma nova região, na imanência do campo fenomenal. Passemos, então, a um exame do sentido desta tal recuperação fenomenológica do mundo. 


\section{O MUNDO RECUPERADO: A “SEGUNDA IMPLICAÇÃO” DA EPOCHÉ FENOMENOLÓGICA}

Pode-se dizer que se a epoché husserliana assume um papel decisivo enquanto estratégia metodológica que nos permite o acesso a esta nova região sobre a qual a fenomenologia irá concentrar o foco de suas investigações, é preciso dizer também que o exercício da referida estratégia deverá obedecer a uma generalização. Husserl visa, fundamentalmente, com tal estratégia, eliminar quaisquer possibilidades de dúvidas e incertezas em relação aquilo que aparece à consciência. Tal generalização encontra-se diretamente ligada à exigência de que o que é revelado como fenômeno seja depurado de tudo o que não for autoevidente e, por isso mesmo, de tudo o que ainda não for inteiramente imune à dúvida. Se inicialmente a epoché é lançada sobre a posição de existência do que se encontra fora de mim, num segundo momento, deverá recair sobre mim mesmo (enquanto ente psicofísico), abrangendo, com isso, todo o domínio empírico-natural que coloca, de um lado, o mundo circundante natural e, de outro, o eu empírico com suas vivências psicológicas. Mas, tal exercício de generalização da epoché não implicaria, nem sequer provisoriamente, em suprimir o transcendente, no sentido de "negar" a existência do mundo.

Husserl estaria, antes sim, renunciando a um modo empírico-natural de consideração do mundo, colocando-o entre parêntesis, para viabilizar, então, com a epoché, o que poderíamos considerar a sua "segunda implicação": o acesso a um modo de consideração "transcendental" do mundo. Por conseguinte, como afirma Husserl, em sua Filosofia Primeira (1923-1924): “[...] no lugar do mundo tout court, nós 
temos somente a consciência 'do mundo'” (HUSSERL, [1924] 1970, p. 346). Tal procedimento desloca-nos a atenção para uma "nova versão" do mundo - o mundo como "correlato intencional", tal como revelado e constituído na consciência. Como lembra Fradique Morujão: "O mundo transforma-se num ser puramente intencional; vale para mim, nesta nova atitude, como fenômeno" (FRADIQUE MORUJÃO, 2002, p. 233).

Se tal estratégia metodológica aproxima-nos, por um lado, da aceitação de um certo idealismo em relação à temática do mundo, isto não implica, contudo, conforme Husserl ressaltou inúmeras vezes, na aceitação de um idealismo como aquele defendido por Berkeley, para o qual "ser é ser percebido" (esse est percipi), sendo que tudo o que é percebido, é percebido como "ideia" no próprio espírito, não havendo nada que o transcenda ou que exista fora dele, que exista fora de uma mente (without a mind) ${ }^{4}$. No $\$ 55$ de Ideias I, Husserl ([1913] 1976) afirma que sua argumentação não nega o mundo como uma realidade empírica que transcende à consciência, nem tampouco transforma o mundo - em seus próprios termos, em uma "ilusão subjetiva" (in subjektiven Schein) - em uma realidade meramente percebida na mente (ou no espírito) sem qualquer relação com o mundo exterior. Insistir em aproximar a posição husserliana do idealismo de Berkeley inplicaria, como o

\footnotetext{
${ }^{4}$ No $§ 6$ da Parte I de Tratado sobre os principios do conhecimento (1710), Berkeley afirma-nos que: "Há algumas verdades tão familiares e óbvias à mente que um homem precisa apenas abrir os olhos para vê-las. Considero que uma delas é esta: que toda abóbada celeste e tudo quanto a Terra contém - numa palavra, todos os corpos que compõem a poderosa estrutura do mundo - não possuem nenhuma existência fora de uma mente [whitout a mind]; que ser é ser percebido ou conhecido. E que, consequentemente, na medida em que eles não são de fato percebidos por mim, ou não existem na minha mente ou na de qualquer outro espírito criado, não devem ter absolutamente existência alguma...". Cf. Berkeley, G. A treatise concerning the principles of human knowledge, I, § 6, p. 25.
} 
próprio Husserl nos diz no referido parágrafo, em não apreender o verdadeiro sentido de sua argumentação .

A ideia husserliana de uma "recuperação do mundo" impõe-nos, então, a seguinte exigência: depurar, através da generalização da epoché, o fenômeno de todo conhecimento que não for autoevidente, sem negar, contudo, a transcendência do mundo. Trata-se, nos termos de Georges Gurvitch (1949), de algo como uma "purificação redutiva". A ideia de uma "recuperação do mundo" da qual nos apercebemos conscientemente impõe-nos, ao menos, através da epoché, uma dualidade fundamental: o deslocamento da atenção do que é transcendente (no sentido do que se encontra fora da consciência) para o que é imanente à consciência. Porém, trata-se não de uma "imanência psicológica", própria de uma consciência empírica (afinal, conforme dissemos, o próprio eu empírico também deverá ser colocado entre parênteses), mas sim, como nos diz Husserl, nas "Cinco Lições" de 1907, de uma "autêntica imanência", domínio "[...] do dado absoluto, da absoluta claridade do estar dado, que exclui toda dúvida que tenha sentido" (HUSSERL, [1907] 1950, pp. 9/10). O campo fenomenal no qual a nova versão do mundo se revela não é senão o da própria consciência transcendental. Se a ideia husserliana de uma "recuperação do mundo" impõe-nos, pelo exercício generalizado da epoché, a passagem do transcendente ao imanente, tal passagem não deve apenas ser entendida como um deslocamento do que se encontra fora de mim para o que se encontra em mim como eu empírico, mas, fundamentalmente, como um deslocamento do transcendente (no sentido do que não é plenamente evidente) para o que se revela, em sua doação originária, como "dado absoluto" ("absoluten Gegebenheit"), em uma evidenciação apodítica na 
subjetividade transcendental .

Acrescenta-se ainda que, através do exercício generalizado da epoché, a consciência transcendental se abre revelando, em sua imanência, a referência intencional aos objetos, que não são senão "conteúdos intencionais". Husserl retém, como herança do pensamento de Franz Brentano (1838-1917), a ideia básica segundo a qual toda consciência é consciência de algo. Recupera-se a concepção aristotélico-tomista da intencionalidade como "objetividade imanente" (immanenten Gegenständlichkeit), porém, para pensá-la, diferentemente de Brentano, no plano de uma subjetividade transcendental, em cuja imanência estariam contidas todas as intenções atuais e possíveis através das quais seriam, nelas próprias, constituídos os "sentidos de ser” (Sein-sinn) do mundo. Daí Emanuel Levinás ([1940] 1974) nos dizer, na década de 40, em um artigo dedicado à obra de Husserl, que: "a intencionalidade guarda o segredo de nossa relação com o mundo" (LEVINÁS, [1940] 1974, p. 31). Pode-se dizer, por este motivo, que os temas da fenomenologia de Husserl levam-nos, inevitavelmente, ao sujeito transcendental no seio do qual se encontra contida toda a objetividade - imanente e intencional - do mundo. O problema da intencionalidade aparece associado à ideia da "constituição dos objetos" na consciência transcendental. A investigação dos elementos que, no ato intencional da consciência pura, são responsáveis pela constituição dos objetos, bem como pelas diferentes modalidades do "aparecer" enquanto tal (a investigação desta subjetividade constituinte) é, nos termos de Lauer, "conhecimento do mundo ele mesmo, uma vez que é na subjetividade e somente na subjetividade que o sentido constantemente idêntico do mundo deve ser encontrado" (LAUER, 1954, p. 37). O mundo re- 
cuperado será, então, considerado como significado e, portanto, apresenta-se como corolário da consciência transcendental que o significa, adquirindo, assim, um caráter absoluto.

\section{CONSIDERAÇÕES FINAIS}

Pode-se dizer, a título de conclusão, que a generalização da epoché fenomenológica - com a sua "dupla implicação" - é o que permite a abertura de um caminho que conduzirá a fenomenologia husserliana à afirmação de um peculiar idealismo no que concerne à temática da relação entre a consciência e o mundo, sem contradizer, contudo, a existência do mundo. Como vimos, nem sequer provisoriamente, Husserl nega a transcendência do mundo; antes sim, renuncia a um modo empírico-natural de consideração do mesmo e, com isso, do ponto de vista epistêmico, se recusa a aceitar um realismo ingênuo, próprio das ciências positivas de sua época. Sendo assim, no caso da atitude natural, não é propriamente o "realismo" (a afirmação da existência do mundo) que Husserl se recusa a aceitar, mas a ingenuidade do realismo adotado pelas ciências que, frente ao seu objeto, não se interrogam pelo sentido desta objetividade. Por outro lado, na medida em que não nega a transcendência do mundo, se afasta de um idealismo, tal como aquele defendido por Berkeley, para quem ser é ser percebido como ideia no espírito, não havendo nada que transcenda a substância espiritual. Tal afastamento não impede, contudo, que Husserl assuma um novo idealismo para o qual a transcendência negada por Berkeley seja, a partir da generalização da epoché, recuperada, sob o modo de "coisa intencionada" e, portanto, constituída, na imanência da 
subjetividade transcendental. Daí podermos dizer que, como correlato intencional da consciência, o "mundo recuperado" seja, nos termos de Husserl, uma "transcendência na imanência" (eine Transzendenz in der Immanenz) - ou ainda, nos termos de suas Conferências de Paris, em 1929, "[...] uma exterioridade objetiva na pura interioridade" (HUSSERL, [1929]1973, p. 4).

Compreender-se-á, enfim, ao menos, em um período do itinerário husserliano que, com a generalização da epoché fenomenológica, "nada se perde", tudo se considera apenas modificado entre parênteses. Daí o próprio Husserl dizer, no $§ 15$ de Meditações Cartesianas, que: "Compreendemos agora pela epoché universal quanto à existência ou inexistência do mundo, que a fenomenologia não nos fez, de fato, perder o mundo como objeto fenomenológico. Nós o conservamos enquanto cogitatum" (HUSSERL, [1931] 1973, p. 75). Como "ciência clarificadora" - cujo olhar visa elucidar, determinar e distinguir o sentido originário do que aparece apoditicamente à consciência como cogitatum - a fenomenologia deve ser, no final das contas, segundo Lauer, "uma ciência do mundo, ou ela não é ciência de nenhuma maneira" (LAUER, 1954, p.36). Em sua versão fenomenológica, o mundo se revela, então, finalmente, na imanência do cogito transcendental.

O exercício generalizado da epoché não implica, conforme vimos, em uma negação do mundo. Como Husserl nos diz, no prefácio da edição inglesa de Ideias I, de 1930: "antes de tudo, o idealismo fenomenológico não nega a existência efetiva do mundo real [...]" (HUSSERL, [1930] 1981, p. 48). A única tarefa deste idealismo é, segundo Husserl, elucidar fenomenologicamente o sentido deste mundo que se forma intencionalmente na própria subjeti- 
vidade transcendental, sem a qual o mundo não poderia "ser objetivo" no sentido pleno do termo. Daí o próprio Husserl dizer, em outra passagem do prefácio da edição inglesa de Ideias I, que: "[...] o mundo real existe sem dúvida, mas possui uma relatividade essencial à subjetividade transcendental [...]" (HUSSERL, [1930] 1981, p. 48). É como se Husserl nos dissesse, então, que o mundo somente é, em sua plenitude, revelado objetivamente, na medida em que o seu sentido é, originariamente, revelado e constituído intencionalmente em nós, no plano de uma subjetividade transcendental. Como nos diz Husserl, no artigo da Enciclopédia Britânica (1927), o mundo tem a sua origem em nós e, “[...] este 'ser-para-nós' do mundo [...] requer clarificação" (HUSSERL, [1927] 1981, p. 28) .

O exercício generalizado da epoché desloca-nos a atenção para a subjetividade transcendental em cuja imanência o mundo se revela como fenômeno, tendo o seu sentido constituído em uma autêntica objetividade imanente. $\mathrm{O}$ que leva Husserl a dizer, então, no curso de 1909, que a fenomenologia retém, pelo exercício da epoché, "o sentido de tudo isso com o qual estou imediatamente em contato" (apud FRAGATA, 1956, p. 113), de um sentido que não só está diante da consciência, mas que brota dela mesma, na medida em que é constituído por seus próprios atos intencionais. A epoché fenomenológica não nos leva, portanto, a criar outro mundo; antes sim, é a operação continuada por intermédio da qual o campo fenomenológico se abre e, ao se abrir, revela, em sua imanência, a constituíção do sentido do mundo, cuja elucidação se tornará o anseio maior da fenomenologia, renovando, uma vez mais, aquilo que Husserl jamais abandonou: o incansável retorno às coisas mesmas.

Abstract: This paper aims to investigate the relationship between the phePHILÓSOPHOS, GOIÂNIA, v. 21, N. 1, P.37-58, JAN./JUN. 2016. 
nomenological epoche and the phenomenological problem of the relationship between the consciousness and the world. Initially, the article examines the first implication of the exercise of epoché: the idea of "loss of the world." Then examines the second implication of this exercise: the idea of "recovery of the world" in the transcendental consciousness. Finally, the article elucidates the specificity of phenomenological idealism of Husserl. The widespread exercise of the epoche does not imply a denial of the existence of the world. The task of this idealism is elucidate the phenomenological sense of this world that is formed intentionally in the transcendental subjectivity.

Keywords: Consciousness; world; epoché; phenomenological idealism.

\section{REFERÊNCIAS BIBLIOGRÁFICAS}

AMERIKS, K. "Husserl's Realism". In: The Philosophical Review, Vol 86, no 4 (Oct, 1977), pp. 498-519.

BERKELEY, G. A treatise concerning the principles of human knowledge. Indianapolis, Cambridge: Hackett Publishing Company, ([1710] 1982).

FINDLAY, J. "Phenomenology and the Meaning of Realism”. In: Pivcevic, E. (ed.) Phenomenology and Philosophical Understanding. Cambridge University Press, 1975.

FINK, E. "Die phänomenologische Philosophie Edmund Husserls in der gegenwärtigen Kritik". In: Kantstudien, XXXVIII, 1933, pp. 319-383.

FRADIQUE MORUJÃO, A. "Mundo e Intencionalidade. Ensaio sobre a noção de mundo na fenomenologia de Husserl". In: Fradique Morujão, A. Estudos Filosóficos - Vol 1. Lisboa: Impressa Nacional - Casa da Moeda, 2002, pp. 173-377.

FRAGATA SJ, J. A Fenomenologia de Husserl como fundamento da filosofia. Braga: Livraria Cruz, 1956.

GURVITCH, G. Les tendances actuelles de la philosophie al- 
lemande. Paris: Librairie Philosophique J. VRIN, 1949.

HUSSERL, E. Die Idee der Phänomenologie - Fünf Vorlesungen. Husserliana (Band II). Netherlands: Martinuos Nijhoff, ([1907] 1950).

Ideen zu einer reinen Phänomenologie und phänomenologischen Philosophie. Erstes Buch: Allgemeine Einführung in die reine Phänomenologie. The Hague, Netherlands: Martinus Nijhoff, [1913] 1976.

"Kant et l'idée de la Philosophie Transcendantale". In: Philosophie première 1923-1924: Histoire critique des idées. Appendice. 3ed. Collection Epimethée. Paris: PUF, [1924] 1970; pp. 299-368.

"Phenomenology", Edmund Husserl's Article for the Encyclopaedia Britannica. In: McCormick, P. \& Elliston, F (editors) Husserl, Shorter Works. Notre Dame, Indiana: University of Notre Dame Press / The Harvester Press, [1927] 1981; pp. 21-35.

Formale und Transzendentale Logik. Versuch einer Kritik der logishen Vernunft. Tübingen: Max Niemeyer, [1929] 1981.

"Author's Preface to the English Edition of Ideas". In: McCormick, P. \& Elliston, F (editors) Husserl, Shorter Works. Notre Dame, Indiana: University of Notre Dame Press / The Harvester Press, [1930] 1981; pp. 43-53.

Cartesianische Meditationen und Pariser Vorträge. Husserliana (Band I). Den Haag, Netherlands: Martinus Nijhoff, ([1931]/ [1929] 1973). 
LANDGREBE, L. "The World as a Phenomenological Problem". In: Philosophy and Phenomenological Research (1), 1940, pp. 38-58.

LAUER, Q. Phénoménologie de Husserl. Essai sur la genèse de l'intentionnalité. Paris: Presses Universitaires de France, 1954.

LÉVINAS, E. En découvrant l'existence avec Husserl et Heidegger. Paris: J. VRIN, ([1940] 1974).

MURALT, A. de The idea of Phenomenology: Husserlian Exemplarism. Evanston: Northwestern University Press, 1974 .

TOURINHO, C. D. C. "Fenomenologia e Ciências Humanas: sobre as considerações de Jean-François Lyotard". In: Carneiro, M. C. \& Gentil, H. S. (orgs) Filosofia Francesa Contemporânea. São Paulo: Cultura Acadêmica Editora, 2009, pp. 202-212.

VANN de PITTE, M. "Introduction to Author's Preface to the English Edition of Ideas". In: McCormick, P. \& Elliston, F (editors) Husserl, Shorter Works. Notre Dame, Indiana: University of Notre Dame Press / The Harvester Press, 1981, pp. 36-42. 